\title{
CORRESPONDENCE
}

\section{Carbon monoxide transfer in the lungs}

\section{To the Editor:}

The Working Party for Standardization of Lung Function Tests has recently produced an impressive compilation of information and recommendations [1]. Nevertheless, some remarks and suggestions regarding the section on gas transfer in the lungs seem justified.

The single-breath test, first devised by M. KROGH [2], is now the most commonly used method for measuring carbon monoxide transfer. It might have been useful to have added a brief outline of the model, as an introduction to the working party's recommendations, as follows. A. KROGH and M. KROGH [3] based their model on the concept that the change in the alveolar pressure of carbon monoxide $(\mathrm{P})$ was proportional to the partial pressure of this gas in the alveoli. Hence, assuming a homogeneous gas distribution in a constant alveolar volume (VA), and no back pressure:

$$
d P=-k P(t) d t
$$

where $\mathrm{k}$ is the rate constant of the decrease of $\mathrm{P}$ with time.

Integrating between time $=0$ and time $=t$, and rearranging:

$$
\mathrm{k}=\frac{1}{\mathrm{t}} \ln \frac{\mathrm{P}_{\mathrm{o}}}{\mathrm{P}_{\mathrm{t}}}
$$

Taking antilogues yields $\mathrm{P}_{\mathrm{t}}=\mathrm{P}_{\mathrm{o}}$, $\mathrm{e}^{-\mathrm{kt}}$. Similar exponential functions of decay adequately describe, such things as the discharge of an electrical capacitor. The rate constant, (time) $)^{-1}$, is the ratio of conductance to capacitance. Hence, in the lung:

$$
\mathrm{k}=\frac{\mathrm{GLCO}}{\beta_{\mathrm{g}} \mathrm{V}_{\mathrm{A}}}
$$

where GLCO is the conductance of the lung for carbon monoxide, and $\beta_{\mathrm{g}}$ is the capacitance coefficient [4] of carbon monoxide in the gas medium. This capacitance coefficient has the dimensions of solubility, and according to Boyle's law $(\mathrm{PV}=\mathrm{nRT})$ equals $(\mathrm{RT})^{-1}$. For an ideal gas at $37^{\circ} \mathrm{C}$, the value of $\beta_{\mathrm{g}}$ is $387.8 \times 10^{-6} \mathrm{~mol} \cdot \mathrm{m}^{-3} \cdot \mathrm{Pa}^{-1}$. Hence, combining Equations (2) and (3) the conductance of the lungs for carbon monoxide (in SI units) is:

$$
\mathrm{GLCO}=387.8 \times 10^{-6} \frac{\mathrm{VA}_{\mathrm{A}}}{\mathrm{t}} \ln \frac{\mathrm{P}_{\mathrm{o}}}{\mathrm{P}_{\mathrm{t}}} \mathrm{mol} \cdot \mathrm{s}^{-1} \cdot \mathrm{Pa}^{-1}
$$

If GLCO (Equation (4) [1]) is in $\mathrm{mmol} \cdot \mathrm{min}^{-1} \cdot \mathrm{kPa}^{-1}, \mathrm{VA}_{\mathrm{A}}$ in $l$ BTPS, and $\mathrm{t}$ in $\mathrm{s}$, then the choice of units (not dimension as stated in paragraph $5.5[1])$ is accounted for by changing the coefficient into 23.27. The following are points of disagreement or suggestions concerning the report.

1) $\boldsymbol{k}$, KCo and KRogh factor. The Kroghs [2, 3] correctly interpreted the proportionality coefficient $\mathrm{k}$ as a rate constant (Equations (1-5) [1]). M. KROGH [2] calculated the lung conductance by multiplying $\mathrm{k}$ with the alveolar STPD volume divided by $\mathrm{PB}-\mathrm{PH}_{2} \mathrm{O}$. This was correct, since she had expressed the quantity of carbon monoxide in STPD volume, and it can be shown that the capacitance coefficient is then $\left(\mathrm{PB}-\mathrm{PH}_{2} \mathrm{O}\right)^{-1}$.

It is stated (paragraph 3.2 [1]) that "The transfer coefficient is also referred to as $\mathrm{T}_{\mathrm{L}} / \mathrm{V}_{\mathrm{A}}$ or as Krogh factor; use of the latter should be limited to circumstances when the result is in absolute units". This seems to imply that $\mathrm{k}$, Krogh factor, $\mathrm{KCO}$, and $\mathrm{T}_{\mathrm{L}} / \mathrm{V}_{\mathrm{A}}$ (or GL/VA) are equivalent, although $\mathrm{k}$ does not fit into the series on account of its dimension. Nevertheless, $\mathrm{k}$ and GLCO/VA give the same information to the clinician, as they differ only by the constant factor $\beta_{\mathrm{g}}^{-1}$ and are identical when expressed as percentage of predicted value. The habit of having the ratio GLCO/VA reported, rather than $\mathrm{k}$, probably stems from our familiarity with similar volumic indices.

Also, it is not clear what is meant by absolute units (paragraphs 2.1 and 3.2 [1]). Maybe, it has to do with Krogh's pertinent remark that $\mathrm{k}$ numerically equals the amount of gas (in volume STPD) that would be transferred per unit time and per unit VA STPD, if the lungs were filled with pure carbon monoxide. It does not, however, introduce absolute units.

2) More on Kco. The working party states that "transfer factor is positively correlated with the lung volume at which the measurement is made (paragraph 2.1 [1]). That may or may not be true in the physiological sense, but cannot be deduced from Equation (5) [1], e.g. where GLCO and VA are not variables, but have the meaning of constants. It is true, however, that errors in the measurement of $\mathrm{VA}_{\mathrm{A}}$ result in proportional errors of the calculated GLCO.

Although the working party does not explicitly state so, one gets the impression that they tend to dissociate the concept GLCO/VA from its origin, i.e. the rate constant k. Firstly, the general definition given $\mathrm{TL}_{\mathrm{L}}=\mathrm{VA}_{\mathrm{A}} \cdot \mathrm{KCO}$ (paragraph 2.1 [1]) is pertinent only to calculations in the single-breath test, and not to the steady-state transfer test. Secondly, the recommendation to calculate the predicted $\mathrm{KCO}$ from the ratio of predicted values in GLCO/TLC (paragraph 7 [1]) further weakens the link with $\mathrm{k}$. Indeed, since the dead space is not substracted from TLC, and since during the single-breath test inspiration is submaximal (within $5-10 \%$ of TLC), the 
Kco predicted as suggested will be underestimated by around $10 \%$. Of course, one might consider $\mathrm{KcO}$ as just an index, useful to the clinician and not referring to any particular method of GLCo measurement.

3) Terminology and symbols. The report proposes the term transfer coefficient for GLCO/VA, or KCO. The choice is unfortunate, since mass transfer coefficient is already the established term for flux divided by concentration difference and, like permeability coefficient, has the formal dimensions (length).(time) $)^{-1}$.

The term transfer factor of the lung is appropriate, if the subscript L in GL means that conductive transfer is not under consideration, and that molecular diffusion and chemical binding with haemoglobin are treated as one factor. Other acceptable names for the same would be: "transferring capacity of the lung" (capacity meaning ability to do something - it would meet the proponents of the old "diffusing capacity" half-way); or "conductance of the lung", which suits the general symbol G for conductance (as used in this text). GL/VA could perhaps be called the "volumic conductance of the lung".

The indifferent use of pressure and pressure gradient (paragraphs 1.2 and 2.1 [1]) is disconcerting, particularly when dealing with gas transfer.

4) Lung volume. The recommendation to use $V_{A}$ obtained by either the closed helium dilution method or plethysmography is probably not indifferent. The volume difference in subjects with obstructive lung disease may amount to more than a litre and would effect the calculated GL in proportion. In some cases, even the use of the closed helium dilution method may overestimate GL, and the use of a plethysmographic VA would aggravate the error. The problem deserves some comment and guidelines in the report.

\section{References}

1. Cotes JE, Chinn DJ, Quanjer PhH, Roca J, Yernault JC. Standardization of the measurement of transfer factor (diffusing capacity). Eur Respir J 1993; 6 (Suppl. 16): 41-52.

2. Krogh M. The diffusion of gases through the lungs of man. J Physiol 1915; 49: 271-300.

3. Krogh A, Krogh M. On the rate of diffusion of carbonic oxide into the lungs of man. Scand Arch Physiol 1910; 23: 236-247.

4. Piiper J, Dejours P, Haab P, Rahn H. Concepts and basic quantities in gas exchange physiology. Respir Physiol 1971; 13: 292-304.

\section{L.M. Lacquet}

UZ Gasthuisberg, Dienst Longziekten, Heresraat 49, B3000 Leuven, Belgium.

\section{REPLY}

\section{From the authors:}

We welcome Lacquet's résumé of the Krogh model, which underlies the standardized method of measuring TLCO, and thank him for pointing out some potential ambiguities in our 1993 report [1]. However, these should not include the Krogh factor (k), which we identify and refer to as such. We do not recommend this index because it is one step removed from the ratio $\mathrm{T}_{\mathrm{L}} / \mathrm{V}_{\mathrm{A}}$ (also designated $\mathrm{KCO}$ ), which is linked numerically to the transfer factor (TLCO), in the units $\mathrm{mmol} \cdot \mathrm{min}^{-1} \cdot \mathrm{kPa}^{-1}$, and the alveolar volume $\left(\mathrm{VA}_{\mathrm{A}}\right)$, in the units $l$ BTPS. The latter two indices are relevant since, as is indicated in the report, the KCO is negatively correlated with $\mathrm{VA}_{\mathrm{A}}$ and not independent of it over the upper half of the vital capacity, as was suggested by KROGH [2]. Hence, the use of KCO does not standardize for alveolar volume. This failure can lead to difficulty in interpretation, which is best overcome by considering all three indices and not $\mathrm{KCO}$ in isolation (paragraph 6.8 [1]).

Lacquet suggests that the report neglects the dilemma posed by the alternative methods of measuring alveolar volume (single-breath versus helium dilution or plethysmography). This is discussed in paragraphs 5.4 and 6.8
[1]. The terminology (paragraph 1.2 [1]), about which Lacquet also has reservations, reflects the application to gas exchange of the guiding principles for harmonization set out in paragraph 8.1 of the previous standardization document [3].

\section{References}

1. Cotes JE, Chinn DJ, Quanjer PhH, Roca J, Yernault JC. Standardization of the measurement of transfer factor (diffusing capacity). Eur Respir J 1993; 6 (Suppl. 16): 41-52.

2. Krogh M. The diffusion of gases through the lungs of man. J Physiol 1915; 49: 271-300.

3. Quanjer $\mathrm{PhH}$, (ed). Standardized lung function testing. Bull Eur Physiopathol Respir 1983; 19 (Suppl. 5): 52.

\section{J.E. Cotes*, D.J. Chinn**, Ph.H. Quanjer ${ }^{+}$, J. Roca ${ }^{++}$, J.-C. Yernault ${ }^{\dagger}$}

University Departments of Physiological Sciences, *Newcastle-upon-Tyne, UK, and +Leiden, The Netherlands. Departments of Respiratory Medicine, **City Hospital, Edinburgh, ${ }^{++}$Barcelona Hospital, Spain and ${ }^{\dagger}$ Erasmus Hospital, Brussels. 